\title{
Implementation of the nutrition and health claim regulation - The case of antioxidants
}

Citation for published version (APA):

de Boer, A., Vos, E., \& Bast, A. (2014). Implementation of the nutrition and health claim regulation - The case of antioxidants. Regulatory Toxicology and Pharmacology, 68(3), 475-487.

https://doi.org/10.1016/j.yrtph.2014.01.014

Document status and date:

Published: 01/04/2014

DOI:

10.1016/j.yrtph.2014.01.014

Document Version:

Publisher's PDF, also known as Version of record

Document license:

Taverne

Please check the document version of this publication:

- A submitted manuscript is the version of the article upon submission and before peer-review. There can be important differences between the submitted version and the official published version of record.

People interested in the research are advised to contact the author for the final version of the publication, or visit the DOI to the publisher's website.

- The final author version and the galley proof are versions of the publication after peer review.

- The final published version features the final layout of the paper including the volume, issue and page numbers.

Link to publication

\footnotetext{
General rights Owners
rights.

- You may freely distribute the URL identifying the publication in the public portal. please follow below link for the End User Agreement:

www.umlib.nl/taverne-license

Take down policy

If you believe that this document breaches copyright please contact us at:

repository@maastrichtuniversity.nl

providing details and we will investigate your claim.
}

Copyright and moral rights for the publications made accessible in the public portal are retained by the authors and/or other copyright owners and it is a condition of accessing publications that users recognise and abide by the legal requirements associated with these

- Users may download and print one copy of any publication from the public portal for the purpose of private study or research.

- You may not further distribute the material or use it for any profit-making activity or commercial gain

If the publication is distributed under the terms of Article $25 \mathrm{fa}$ of the Dutch Copyright Act, indicated by the "Taverne" license above, 


\title{
Implementation of the nutrition and health claim regulation - The case of antioxidants
}

\author{
Alie de Boer ${ }^{\mathrm{a}, *}$, Ellen Vos ${ }^{\mathrm{b}}$, Aalt Bast ${ }^{\mathrm{a}}$ \\ a Department of Toxicology, Faculty of Health Medicine and Life Sciences, Maastricht University, Maastricht, The Netherlands \\ ${ }^{\mathrm{b}}$ Department of European and International Law, Faculty of Law, Maastricht University, Maastricht, The Netherlands
}

\section{A R T I C L E I N F O}

\section{Article history:}

Received 30 October 2013

Available online 10 February 2014

\section{Keywords:}

EFSA

European Commission

Food law

Scientific substantiation

Functional ingredients

Oxidative stress

Antioxidants

Nutrition research

Multifactorial

\begin{abstract}
A B S T R A C T
This article analyses the consequences of the implementation of the nutrition and health claim regulation in the field of food products containing antioxidants or food products claiming antioxidant activity. To this end, it first examines the origin and creation of the regulation and the involvement of EFSA in assessing scientific substantiation of health claims. Three criteria are regarded as critical in EFSA's opinions on the scientific substantiation of a health claim: the claimed effect (i) is well defined; (ii) is a clear beneficial physiological effect; and (iii) shows a cause effect relationship with the consumption of the food or functional ingredient. These criteria have implications for the research requested to substantiate health claims, although these implications do not all seem to fit nutrition research as it is currently executed. Looking at antioxidants, the complexity of the mechanisms and actions of antioxidants is not recognised by the criteria used to evaluate proposed health claims, nor by the methodologies used to assess the effects of antioxidants. These criteria should be adjusted with novel scientific insights after consulting stakeholders.
\end{abstract}

(c) 2014 Elsevier Inc. All rights reserved.

\section{Introduction}

After several Europe-wide food scares in the 1990s, there was a call to reform European food law (Hoad, 2011; Levidow and Carr, 2007; van der Meulen and van der Velde, 2008a; van der Meulen, 2009). Different advisory papers from the European Commission (EC) as the Green Paper (1997) and White Paper on Food Safety (2000), describing the vision on food law followed (European Commission, 1997, 2000). In 2002 the 'Regulation (EC) No 178/2002 of the European Parliament and of the Council of 28 January 2002 laying down the general principles and requirements of food law, establishing the European Food Safety Authority and laying down procedures in matters of food safety', also called the General Food Law (GFL), entered into force (European Parliament and the Council, 2002; Levidow and Carr, 2007). This GFL is seen as the cornerstone of the European food law today (Szajkowska, 2009).

In addition to the GFL, the EU has adopted a great number of specific rules dealing with various aspects of the food chain and specific food components, as the use of flavourings (European Parliament and the Council, 2008), microbial criteria for food

\footnotetext{
* Corresponding author. Address: Department of Toxicology, Faculty of Health Medicine and Life Sciences, Maastricht University, P.O. Box 616, 6200 MD Maastricht, The Netherlands.

E-mail address: a.deboer@maastrichtuniversity.nl (A. de Boer).
}

products (European Commission, 2010), or food information to consumers (European Parliament and the Council, 2011). Importantly, one of these specific rules deals with claims and statements made on food products about the effect of the product after intake: 'Regulation (EC) No 1924/2006 of the European Parliament and of the Council of 20 December 2006 on nutrition and health claims made on foods', also called the Nutrition and Health Claim Regulation (NHCR) (European Parliament and the Council, 2006). This regulation requires the information on the label provided to consumers to be based on scientific evidence, to prevent consumers from being misled by unclear or incorrect information and false claims (Hoad, 2011; Moors, 2012). The use of a claim is allowed or refused by the EC, after consulting the expert opinion of the European Food Safety Authority (EFSA) on the submitted claim (European Food Safety Authority, 2013a).

The NHCR entered into force on 1 July 2007, regulating all communications about nutritional content and health benefits of a product. All proposed claims were assessed by EFSA and documented in the so-called 'EFSA opinions'. Remarkably, the opinions gave negative advices on almost all suggested health claims in the field of food products or functional ingredients containing antioxidants or claiming antioxidant activity as shown in Table 1 below. This table provides an overview of proposed, authorised and nonauthorised claims on antioxidants. Only eight claims out of 230 on antioxidant activity were assessed positively and subsequently 
Table 1

Claims on antioxidants in EU Register on nutrition and health claims (European Commission, 2012b).

\begin{tabular}{llll}
\hline $\begin{array}{l}\text { Search term in } \\
\text { register }\end{array}$ & $\begin{array}{l}\text { Proposed } \\
\text { claims }\end{array}$ & $\begin{array}{l}\text { Authorised } \\
\text { claims }\end{array}$ & $\begin{array}{l}\text { Non-authorised } \\
\text { claims }\end{array}$ \\
\hline $\begin{array}{l}\text { Antioxida } \\
\text { Phenol }^{\mathrm{a}} \mathrm{b}\end{array}$ & 156 & 0 & 156 \\
Oxida $^{\mathrm{a}}$ & 26 & 1 & 25 \\
\hline
\end{tabular}

\footnotetext{
a Search term as entered in register.

b Both as substance and effect.

${ }^{c}$ Includes the positive opinions within phenol ${ }^{\mathrm{a}}$ as search term.
}

authorised by the EC to be used on products, viz. seven claims on vitamins and minerals, one claim on olive oil polyphenols (European Commission, 2012b).

EFSA's negative opinions led to a denial of proposed claims on antioxidants as property, ingredient, protector against oxidative damage or in maintaining the immune system (European Commission, 2012b). The positive opinions from EFSA on water-soluble tomato concentrate I and II (NDA Panel EFSA, 2009b, 2010a) and on cocoa flavonoids (NDA Panel EFSA, 2012b) are not taken into account here. The claimed health benefits of these products are not associated with antioxidant activity, and are not specifically regarded as a consequence of antioxidants as the active ingredient.

As a result of the negative opinions of EFSA on antioxidant related health effects and subsequent declines of proposed health claims by the EC, today no statements about ingredients acting as antioxidants or their health effects are allowed to be made, except for claims based on the previously mentioned positive opinions (Europe Press Releases, 2006; European Commission, 2012b). For industrials in this field, who are not able to communicate the benefit of their product, this may be a reason to no longer focus their research on antioxidants ( Ernst \& Young, 2012; Hoad, 2011).

The EC as regulator considers the regulation of health claims a stimulation for the industry to innovate and to develop healthier foods or food products with functional benefits, thereby improving their competitiveness (Flynn, 2012; Moors, 2012). Nevertheless, several industrials view the NHCR suppresses creativity and innovations and notice flaws in the regulation and its implementation, with unclear criteria on the required scientific evidence to substantiate a claim. Other parties, critically following the regulation, however state that extensive guidance is offered to applicants by several guidance documents from EFSA (Ernst \& Young, 2012; Flynn, 2012; Gilsenan, 2011; Hoad, 2011; Moors, 2012). These parties expect uncertainty on the evidence needed to substantiate a claim certainly will decrease even more with the list of approved claims published in December 2012 as annex to 'Commission Regulation (EU) No 432/2012 of 16 May 2012 establishing a list of permitted health claims made on foods, other than those referring to the reduction of disease risk and to children's development and health' (Europe Press Releases, 2006; European Commission, 2012a; Gilsenan, 2011; Moors, 2012). Although many opinions and critiques on the regulation and the used assessment criteria were expressed, no critical evaluation has been written defining the problems that arise from the implementation of the NHCR.

This paper aims to fill that lacuna. Therefore, this paper analyses the implementation of the NHCR, taking food products containing antioxidants or claiming antioxidant activity as a case study. The mechanism of action of antioxidants is currently highly debated, which makes this case study very timely. Two research questions are put forward: (i) Which criteria are used to assess the scientific substantiation of health claims; and (ii) Whether these criteria are suitable to assess a claim.

In this paper, first the framework of the NHCR is described, followed by the establishment of EFSA and the role of EFSA in the
NHCR. Subsequently different opinions on claims of antioxidants are analysed to answer the research questions, which is followed by the conclusions of this paper.

\section{Nutrition and Health Claim Regulation: realisation and definitions}

The Nutrition and Health Claim Regulation entered into force in 2007 , and was preceded by scientific projects and advisory papers.

\subsection{Creating regulation on claims}

Increasing interest in the concepts of functional foods and health claims led the European Union and International Life Sciences Institute Europe (ILSI Europe) to start the FUFOSE (Functional Food Science) project in 1995, to create an approach for evidence needed to support the development of functional foods, based on science (Diplock et al., 1999; European Food Information Council). This research project also addressed the concept of health claims. The final document in 1999 defined two types of health claims: (i) enhanced function claims, claiming actions of a product going further then their established functions in the body and (ii) reduction of disease risk claims, claiming the consumption of a specific food or functional ingredient will help to decrease the risk of a specific condition (Diplock et al., 1999). To implement the conclusions and principles of the FUFOSE project, the PASSCLAIM (Process for the Assessment of Scientific Support for Claims on Foods) project was started, to define criteria for studies to substantiate both types of claims (Aggett et al., 2005; European Food Information Council). The final document of PASSCLAIM, published in 2005, defined criteria for substantiation of a claim, although it was emphasised these criteria only serve as a template for the evaluation process and could provide guidance for applicants; there was still a need to include expert advice in development of regulation on health claims (Aggett et al., 2005). PASSCLAIM also proposed a third type of health claim, viz. the nutrient function claim, closely related to the enhanced function claim. Where enhanced function claims describe functions of the product beyond established functions in the body, a nutrient function claim describes the physiological role of a nutrient in growth, development and normal functions of the body, based on generally accepted and well-established knowledge (Aggett et al., 2005).

In the meantime, introducing specific provisions to manage nutrition and function claims was proposed in the White Paper on Food Safety, to harmonise legislation throughout the European Union and to ensure a high level of consumer protection (European Commission, 2000, 2001). In May 2001 this was followed by the discussion paper on nutrition claims and functional claims, describing issues from invited comments of over 90 stakeholders to take into consideration in upcoming legislative acts. These comments led to the inclusion of health claims in the same proposed regulation as nutrition claims, where the first idea was to create separate legislation for the different types of claims (European Commission, 2001, 2003a). In 2003 the final proposal to regulate nutrition and health claims in Europe was presented by the EC (European Commission, 2003b; European Food Information Council). The development of the NHCR is depicted in Fig. 1 below.

\subsection{The Nutrition and Health Claim Regulation}

Since 2006, claims on antioxidants and other active ingredients in food products are regulated by Regulation 1924/2006 of the European Parliament and of the Council of 20 December 2006 on nutrition and health claims made on foods, also called the NHCR (European Parliament and the Council, 2006). The NHCR is a more 


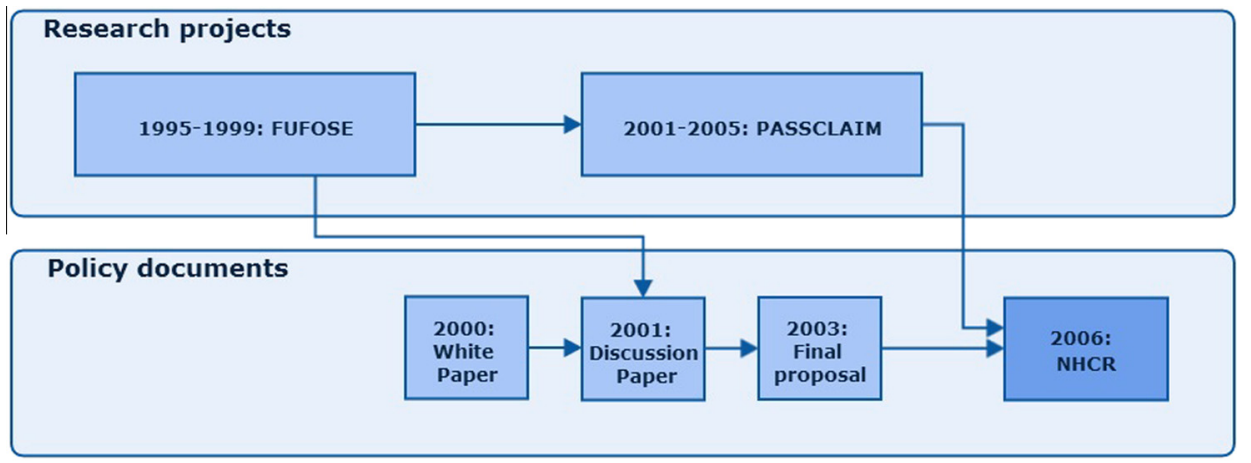

Fig. 1. Development of the NHCR.

specific regulation within the European food law which aims to ensure a high level of protection for consumers and to facilitate their choice by making sure claims are scientifically substantiated, and is intended to improve the free movement of goods in the internal market by harmonising the different national regulations of Member States (Moors, 2012). The regulation deals with all messages voluntarily put on the label in any form including graphic representation, stating, suggesting or implying the food has particular characteristics (European Parliament and the Council, 2006). Thereby, the NHCR prevents consumers from being misled due to unclear or incorrect information and false claims (Hoad, 2011; Moors, 2012).

Recital 1 of the preamble of the regulation states why the NHCR was deemed necessary: 'In order to ensure a high level of protection for consumers and to facilitate their choice, products put on the market (...) should be safe and adequately labelled.' (European Parliament and the Council, 2006). The NHCR makes it possible to communicate benefits to consumers about food products, if this claim is substantiated by generally accepted scientific evidence, as described in article 6: '1. Nutrition and health claims shall be based on and substantiated by generally accepted scientific evidence. 2. A food business operator making a nutrition or health claim shall justify the use of the claim.' (European Parliament and the Council, 2006; van der Meulen and van der Velde, 2008b). A claim is only allowed for use under the general conditions of article 5(1), making sure the food or functional ingredient is present in a significant quantity, is effective with an amount reasonably consumed in the diet, and leads to a beneficial nutritional or physiological effect (European Parliament and the Council, 2006).

The concept claim is defined in article 2(2)(1): 'Claim' means any message or representation, which is not mandatory under Community or national legislation, including pictorial, graphic or symbolic representation, in any form, which states, suggests or implies that a food has particular characteristics' (European Parliament and the Council, 2006). Claims under the NHCR are divided into nutrition claims on the nutritional properties of the ingredient or food product, and health claims on the relationship between the ingredient or food product and a beneficial effect on health (European Parliament and the Council, 2006).

Health claims can be divided in three categories: (i) article 13.1 claims: general function claims implying a health benefit based on accepted scientific evidence, as 'copper contributes to the protection of cells from oxidative stress', (European Food Safety Authority, 2013b); (ii) article 13.5 claims: new function claims implying a health benefit based on newly developed scientific evidence, giving the option to request protection of proprietary data, as 'water-soluble tomato concentrate I and II helps maintain normal platelet aggregation, which contributes to healthy blood flow', (European Food Safety Authority, 2013c); and (iii) article 14 claims: claims on (a) the reduction of disease risk as 'plant sterols and plant stanol esters have been shown to lower/reduce blood cholesterol. High cholesterol is a risk factor in the development of coronary heart disease.' or on (b) children's development and health as 'essential fatty acids are needed for normal growth and development of children' (European Commission, 2012b; European Food Safety Authority, 2013d; European Parliament and the Council, 2006).

In article 13.1 of the NHCR, the list of approved health claims is introduced (European Parliament and the Council, 2006). This list, found in the annex of Regulation 432/2012 ${ }^{1}$, describes all authorised 13.1 and 13.5 health claims (except those based on proprietary data), currently 228 (European Commission, 2012a,b, 2013; European Food Safety Authority, 2013b). Since all proposed article 13.1 claims have been reviewed by EFSA, only article 13.5 claims can be submitted to be on this list after authorisation by the EC (Verhagen et al., 2010).

\section{European Food Safety Authority: establishment and role in the NHCR}

Next to introducing legal principles and requirements of food law and procedures for food safety matters, the GFL also establishes the European Food Safety Authority (EFSA) (European Parliament and the Council, 2002).

\subsection{Establishment of EFSA}

The establishment of EFSA as an independent agency was considered necessary to ensure the functional separation of risk assessment (review of scientific evidence to evaluate risks and hazards) and risk management (handling of the identified risks) (European Food Safety Authority, 2013e, f; Levidow and Carr, 2007; Szajkowska, 2009). The need for improving this separation was suggested by different signalled problems in the use of earlier risk assessments, such as the lack of independence and conflicting outcomes of risk assessments of different expert committees. Also, increasing transparency was needed for all stakeholders in the processes and judgements forming the final expert advice (Levidow and Carr, 2007). EFSA was founded to regain public confidence through the use of independent, harmonised scientific advice by making sure risk assessment is undertaken in an independent, objective and transparent manner (European Parliament and the Council, 2002; Levidow and Carr, 2007; Moors, 2012). The establishment of EFSA was seen by the EC as the most effective way to increase consumer confidence and to address the growing need

\footnotetext{
${ }^{1}$ Regulation 432/2012 is amended by Commission Regulation (EU) No 536/2013 of 11 June 2013 amending Regulation (EU) No 432/2012 establishing a list of permitted health claims made on foods other than those referring to the reduction of disease risk and to children's development and health, adding six article 13.1 claims to the list published in the Annex.
} 
for a solid science-based policy (Health and Consumer Protection Directorate General, 2000). According to European Commissioner Byrne in 2002, the independence of EFSA would make sure the scientific risk assessment would not be overruled by policy considerations or other factors (Byrne, 2002).

The establishment of EFSA is described in chapter III of the GFL. Article 22 states the establishment and mission of the authority, by describing EFSA will provide scientific advice and support for all legislation in the European Union relating to food and feed safety and it will provide independent information on and communicate about characterisation and monitoring of risks. Thereby the authority contributes to a high level of protection of human life and health (European Parliament and the Council, 2002). EFSA's tasks are described in article 23 and entails tasks as providing scientific opinions, identifying and characterising emerging risks and establishing a networking system (European Parliament and the Council, 2002).

Article 29 defines the scientific opinions which can be issued by EFSA: 'The Authority shall issue a scientific opinion: (a) at the request of the Commission, in respect of any matter within its mission, and in all cases where Community legislation makes provision for the Authority to be consulted; (b) on its own initiative, on matters falling within its mission.' (European Parliament and the Council, 2002). The possibility of diverging opinions and how to resolve such a situation is addressed in article 30 (European Parliament and the Council, 2002).

Articles 37 to 42 describe the way EFSA, its staff members and members of the panels ensure independence, transparency and confidentiality. Article 37 states the independence of the authority and members, which became very important after the different food incidents in Europe. External influence of the risk assessment process is hereby reduced as much as possible. Article 38 addresses transparency, by describing in paragraph 1 all items that are made public as the minutes and notes of meetings, declarations of interest and the opinions and the information on which they are based (European Parliament and the Council, 2002).

Corporate documents of EFSA describe different topics as strategy and independence more thoroughly than illustrated in the GFL, in which these topics are addressed briefly. These corporate documents describe policy and strategy; operating rules; selection of experts and dealing with science; independence; transparency; quality; financial provisions and annual work programmes (European Food Safety Authority, 2013g; van der Meulen and van der Velde, 2008c).

\subsection{Role of EFSA in the NHCR}

Although the main focus of EFSA was the safety of food, the European Commission and the European Parliament considered EFSA the most suitable agency to review proposed health claims (Hanekamp et al., 2013).

Within the NHCR, EFSA was given four tasks by the European Commission: (i) give advice on establishment of the positive list of permitted health claims; (ii) give opinions on individual applications for health claims; (iii) provide guidance for applicants on the authorisation process of health claims and (iv) give scientific advice on nutrient profiles (European Commission, 2007; European Food Safety Authority, 2013h).

The first and second task were combined with assessing article 13.1 health claims by delivering scientific opinions about the proposed claims (European Food Safety Authority, 2013a; Moors, 2012; Silano and Silano, 2008). After filtering and clustering by the EC, from the more than 44,000 claims which were proposed by all Member States before 31 January 2008 only 4,637 were left for EFSA to assess (European Food Safety Authority, 2013b; Verhagen et al., 2010). The assessment procedure is described in article
13(3) of the NHCR, and a specific informative document on the procedure was published by EFSA in 2010 (European Food Safety Authority, 2010; European Parliament and the Council, 2006). The groups of claims were evaluated by EFSA, taking into account the conditions of use and references provided by associated health claims (European Commission, 2007; European Food Safety Authority, 2010).

With these requests to EFSA, the EC formulated Terms of Reference giving EFSA several aspects to consider when issuing opinions on these health claims (European Commission, 2007). These aspects followed from the previous research performed on nutrition and health claims, as the PASSCLAIM project (Aggett et al., 2005; European Food Information Council). The final document of PASSCLAIM defined six criteria to be checked for data submitted as scientific substantiation of a claim, on characterisation of the food, substantiation of the claim, the use of valid markers, the significance of the effect and the totality of data (Aggett et al., 2005). In the Terms of Reference, this was translated to the following main aspects to be considered by EFSA: (i) if adequate information is provided on characteristics of the food or functional ingredient; (ii) if the beneficial effect is substantiated by generally accepted scientific evidence; and (iii) how important the food is for the claimed effect (European Commission, 2007).

With the information provided in the Terms of Reference, EFSA was able to set up an initial screening tool to see if sufficient information was provided to evaluate a claim. Claims were sent back to the EC if clarity or additional information was needed, on: (i) the scope of the claim; (ii) the health relationship of the claim; (iii) the wording of the claim; (iv) characterisation of foods or their conditions of use; (v) definitions of a combination of constituents; or (vi) when claims were written in other languages than English (European Food Safety Authority, 2008).

After finishing this screening procedure and receiving additional information on the proposed claims if necessary, all claims were evaluated by EFSA following the legal framework set by the NHCR (Flynn, 2012). As described, scientific substantiation is considered to be the main aspect for justifying a nutrition or health claim. Provided scientific evidence was used to examine different aspects of the claim, based on the criteria set by the Terms of Reference (NDA Panel EFSA, 2011a). Scientific data supporting the claims were structured by their relevance to the claim, preferring human intervention studies, human observational studies or other human studies, and with non-human data as supportive evidence (European Commission, 2008).

The advices of EFSA on the evaluated scientific data, described in the EFSA opinions, were published in batches in the EFSA Journal. The recommendations of EFSA were discussed by the EC, making the final decision accepting or rejecting a claim. It is also the responsibility of the EC the claim is well understood by consumers (European Food Safety Authority, 2013a; Moors, 2012). The full process from the NHCR entering into force to the final decision of the EC is presented in Fig. 2 below.

From the 4637 proposed general function claims, 2758 were examined by EFSA. After publishing 341 scientific opinions, the claims on different foods or food ingredients which received a favourable opinion by EFSA and were authorised by the EC were adopted in Regulation 432/2012, the list of positive article 13.1 and 13.5 health claims. This left 222 authorised article 13.1 health claims, entering into force in December 2012 (European Commission, 2012a; European Food Safety Authority, 2013b; European Food Safety Authority, 2012) with an additional 6 claims put on the list in May 2013 (European Commission, 2013). The procedure starting with 44,000 proposed claims to the 228 claims on the positive list is shown in Fig. 3 below.

These permitted claims are allowed to be used by all food manufacturers throughout the European Union. Assessment of article 


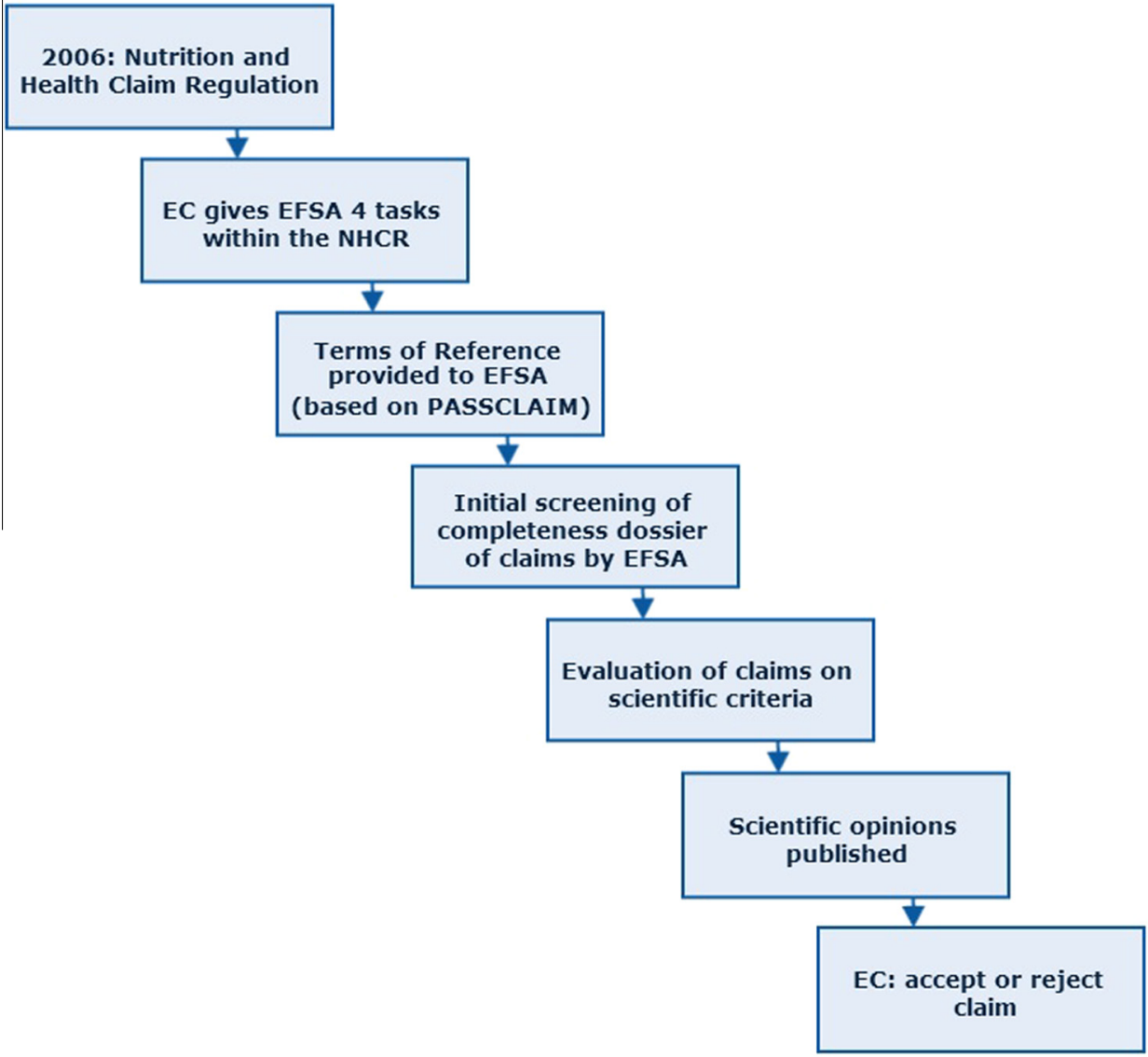

Fig. 2. From NHCR to final decisions on claims.

13.5 and 14 claims, the new function claims and claims on the reduction of disease risk or children's development and health is a continuous process, as food manufacturers are always able to submit new dossiers on these claims. All proposed claims are assessed on a case-by-case basis (European Food Safety Authority, 2012; European Food Safety Authority, 2013c; Moors, 2012; Verhagen et al., 2010).

\section{Health claims on antioxidants: assessment and opinions}

As described in the previous section, scientific opinions on health claims under the NHCR are provided by EFSA. These opinions are used by the Commission to decide on permitting or rejecting a claim (European Food Safety Authority, 2013a). This section will examine into detail the assessment of health claims concerning antioxidants. To this end, first a brief overview of the actions of antioxidants will be given.

\subsection{Mechanisms of action of antioxidants}

In the scientific debate on the actions of antioxidants ranging opinions are given: antioxidants are for example seen as omnipotent life savers or as toxic compounds. New insights in the mechanism of action of antioxidants are important for the substantiation of health claims on antioxidants by EFSA. These insights however are not used yet in the substantiation of health claims on antioxidants where the main focus was only on radical scavenging by antioxidants. In that way, several misconceptions prevail and therefore consensus is not reached (Bast and Haenen, 2013; European Food Safety Authority, 2013a).
Antioxidants, naturally occurring in different food products or produced synthetically, balance reactive species in the human body by acting as a direct or indirect scavenger of reactive species or by inhibiting their production (Carocho and Ferreira, 2012; Halliwell, 1996). The definition of an antioxidant by Halliwell (2007) is: 'any substance that delays, prevents or removes oxidative damage to a target molecule' (Halliwell, 2007). Some of the reactive oxygen species (ROS) are free radicals, which easily react with other molecules (Carocho and Ferreira, 2012; Halliwell, 1996; Malireddy et al., 2012). Their formation is an essential part of normal metabolic processes and has useful functions as to make it possible to use oxygen as electron acceptor in mitochondria and to protect from foreign invading organisms (Carocho and Ferreira, 2012; Halliwell, 1996, 2007; Masella et al., 2005). The classic view is that when production of ROS exceeds the protective antioxidant capacity, oxidative stress occurs. Oxidative stress can be defined as 'a serious imbalance between the generation of ROS and antioxidant protection in favour of the former, causing excessive oxidative damage' (Halliwell, 2011; Weseler and Bast, 2010). During this process reactive species attack healthy cells, especially proteins, DNA and RNA, sugars, and lipids, leading to structural damage of these cells (Carocho and Ferreira, 2012; Halliwell, 2007). Even though the occurrence of oxidative stress is mostly not the primary cause of a disease, it is an important secondary phenomenon linked to several processes as the ageing process, and neurological disorders (Alzheimer disease, Parkinson disease), cardiovascular diseases (ischemia, atherosclerosis), pulmonary diseases (COPD, fibrosis) and metabolic diseases (diabetes) (Carocho and Ferreira, 2012; de Vries et al., 2008; Halliwell, 1996; Malireddy et al., 2012; Masella et al., 2005; Preiser, 2012; Reuland et al., 2013). 


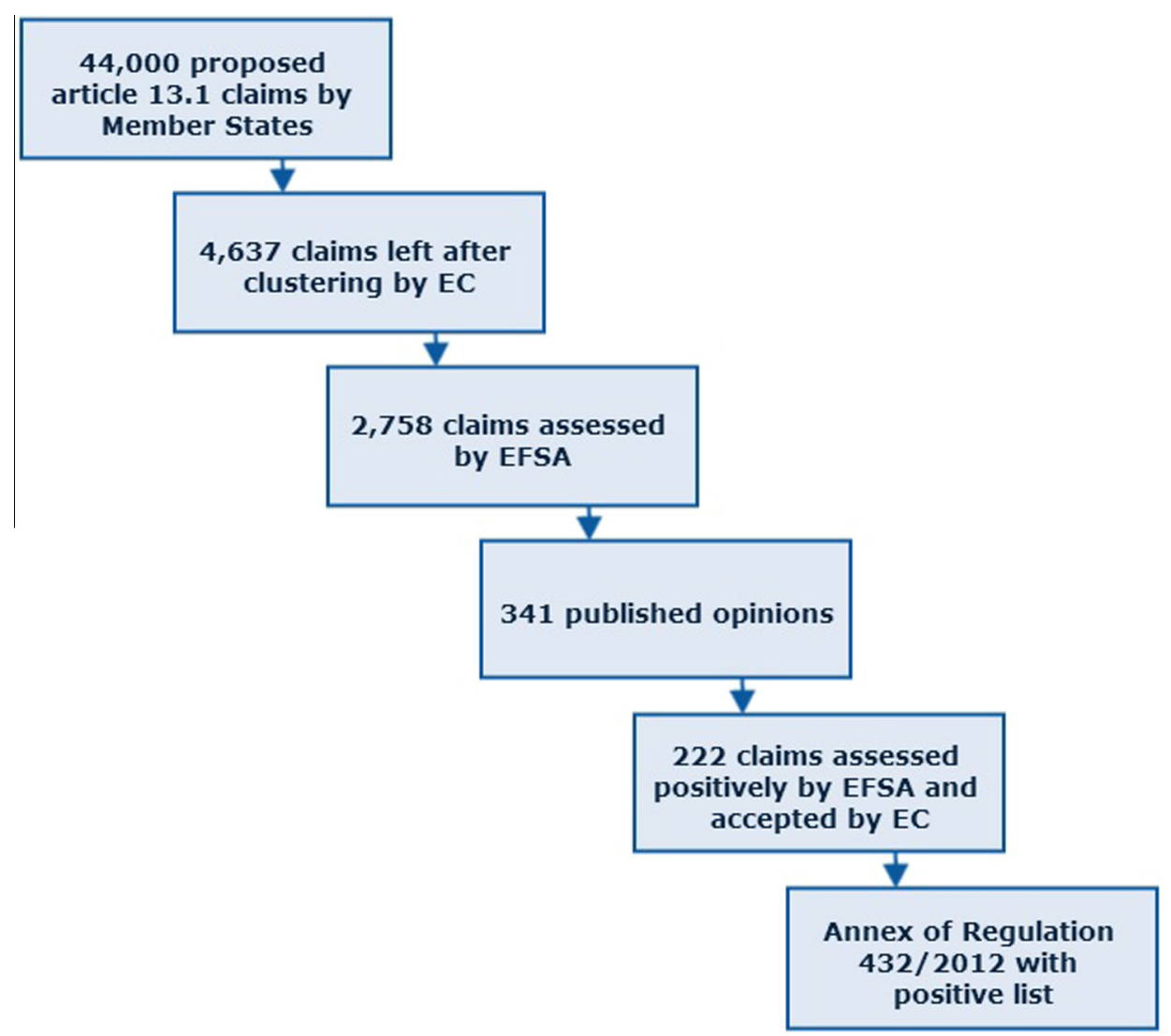

Fig. 3. Assessment procedure article 13.1 claims: Proposed claims to accepted claims.

In the current view on the mechanisms of action of antioxidants, it is increasingly recognized that antioxidants not only act as radical scavengers, but that they indirectly influence endogenous ROS protecting enzyme systems through posttranscriptional mechanisms, activated via the antioxidant response elements found in the promoter region of encoding genes (Nguyen et al., 2004). Antioxidant response elements influence gene expression, for example via the Nrf2 (nuclear factor (erythroid derived 2)-like 2 ) mediated transcription. The interaction between antioxidant response elements and Nrf2 is shown by Nrf2 proteins binding to the sequence of the antioxidant response elements, positively regulating its activity. When an inhibiting cofactor as Keap1 (Kelch-like ECH-associated protein 1) binds Nrf2 in the cytoplasm, the translocation of Nrf2 to the nucleus is inhibited and the antioxidant responsive element DNA sequences will not be activated (de Vries et al., 2008; Masella et al., 2005; Reuland et al., 2013). Oxidative stress activates uncoupling of the inactive Keap1-Nrf2 complex through oxidation of cysteine residues of the complex and thereby altering the structure of Keap1, so the binding of Nrf2 in the nucleus can take place. Thus heterodimers of Nrf2 with transcription factors are formed, which bind to the antioxidant response elements and thereby induce the transcription of phase II antioxidant enzymes, as shown in Fig. 4 (Bast and Haenen, 2013; Owuor and Kong, 2002; Reuland et al., 2013). Moreover, many antioxidants possess anti-inflammatory activity which may contribute to their action (Hazewindus et al., 2012). Different flavonoids show antiinflammatory effects by inhibiting the PARP-1 (poly(ADP-ribose) polymerase-1). PARP-1 plays a role in the repair process of oxidatively damaged DNA. Moreover, it is a cofactor in the action of the transcription factor $\mathrm{Nf}-\kappa \mathrm{B}$, which is activated by ROS and produces pro-inflammatory mediators (Fig. 4). Dietary antioxidants (like flavonoids as quercetin, fisetin and tricetin) prevent the ROS mediated activation of $\mathrm{Nf}-\kappa \mathrm{B}$ and inhibit (via PARP-1 inhibition) the Nf- $\kappa \mathrm{B}$ induced gene expression (Geraets et al., 2007). In that way antioxidants are anti-inflammatory compounds and display a broad bio-active role. The term 'bioactive' has been suggested (Bast and Haenen, 2013).

Although cells can react to reactive species by up-regulating endogenous antioxidant synthesis, to keep this delicate balance dietary antioxidants are needed. Resilience to stress might be improved by additional antioxidants (Bast and Haenen, 2013). Dietary antioxidants are naturally found in fruits and vegetables in the forms of flavonoids, vitamins $\mathrm{C}$ and $\mathrm{E}$ and carotenoids, whilst also phenolic acids, minerals and organosulfur compounds can act as antioxidants (Carocho and Ferreira, 2012; Heim et al., 2002; Langseth, 1995). Next to this, several synthetic antioxidants are introduced in foods mostly to prevent food oxidation (Carocho and Ferreira, 2012).

Antioxidants can also turn into pro-oxidants when the balance between free radicals and antioxidants shifts. This would lead to oxidative stress, i.e. increasing the risk of onset of disease as Alzheimer disease and inflammatory diseases, as described above (Carocho and Ferreira, 2012; Preiser, 2012). Not only oxidative stress but also oxidized metabolites of antioxidants are shown to uncouple the inactive Keap1-Nrf2 complex. Thereby the endogenous antioxidant system becomes activated (Forman et al., 2013).

\subsection{Assessment of health claims on antioxidants}

After the initial screening of over 40,000 proposed claims by the Commission, EFSA assessed each specific food and health relationship forming the basis of a health claim. The three criteria shown to be used for this assessment procedure are based on initiatives as FUFOSE and PASSCLAIM as described in Section 2.1, and are found 


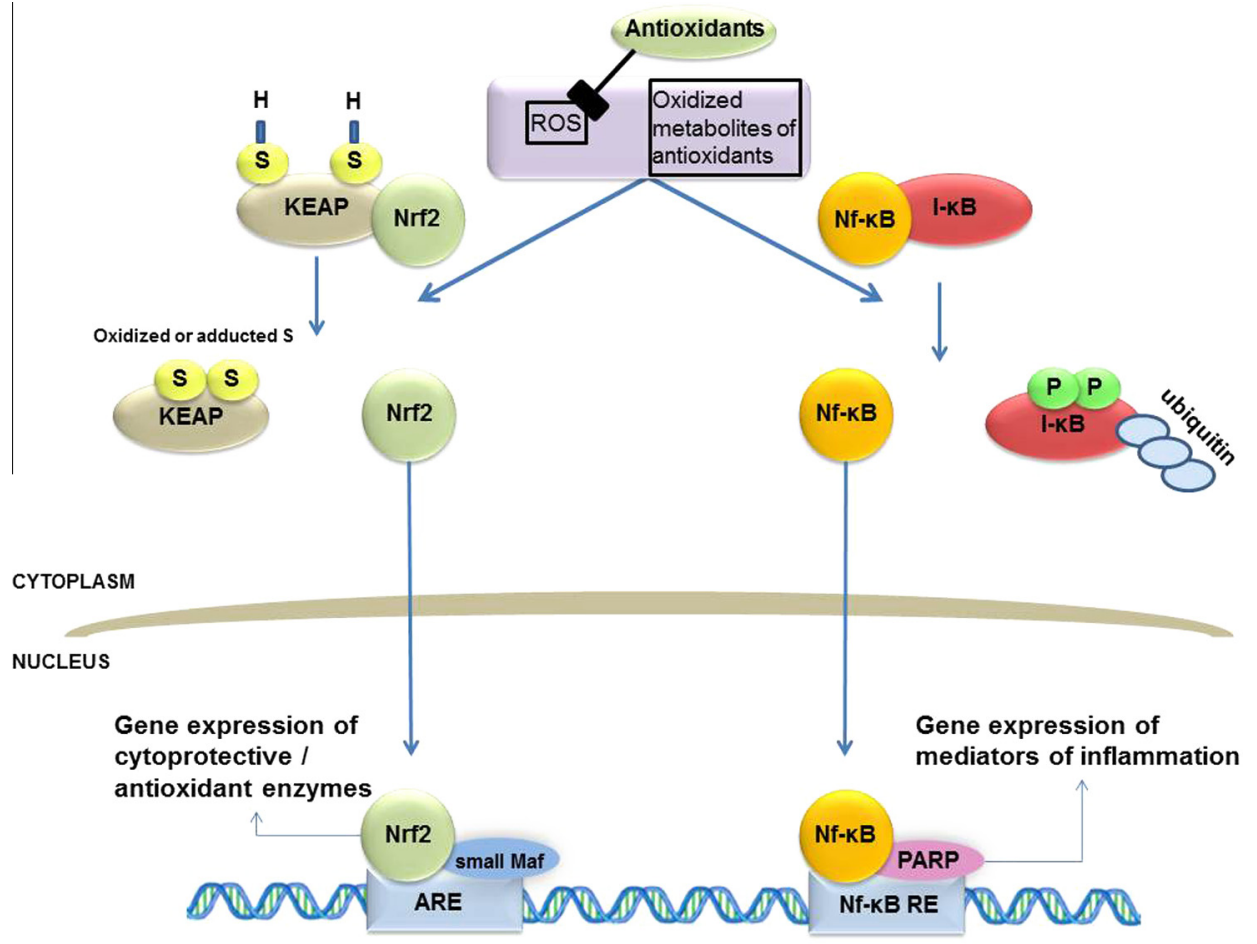

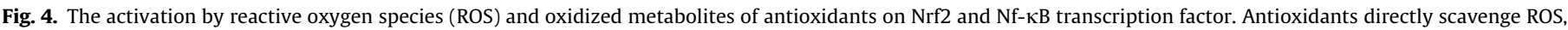

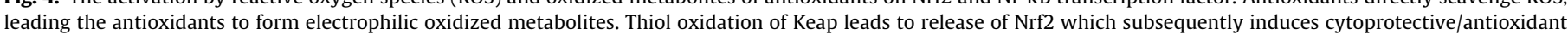
enzymes via antioxidant response elements (ARE).

Table 2

Assessment criteria scientific opinions (NDA Panel EFSA, 2011a).

\begin{tabular}{cl}
\hline & Criteria \\
\hline I & The food or functional ingredient is defined and characterised \\
II The claimed effect is defined \\
The claimed effect is a beneficial physiological effect \\
III A cause and effect relationship is established between the consumption \\
of the food or functional ingredient and the claimed effect
\end{tabular}

in all opinions published by EFSA (Table 2). The criteria were developed by EFSA following the Terms of Reference provided by the EC, and are not only used when reviewing health claims on antioxidants, also assessment procedures of other health claims follow these criteria (NDA Panel EFSA, 2011a).

Each claimed relationship between a food or functional ingredient and a beneficial physiological effect is assessed separately with these criteria. When the outcome is favourable on all three criteria, the following aspects are reviewed to evaluate the claim:

- If it is reasonable the quantity of the food needed to obtain the claimed effect can be consumed within a balanced diet;

- If the proposed wording reflects the scientific evidence;

- If the proposed wording complies with the criteria for use specified in the NHCR (truthful, clear, reliable and useful to the consumer);

- If the proposed conditions and restrictions of use are appropriate (e.g. the presence of certain substances);

- And in case of an article 13.5 or 14 claim, if proprietary data is needed for the substantiation (NDA Panel EFSA, 2011a).

These aspects are assessed for every claim on a case-by-case basis. A favourable outcome on all three criteria leads to a positive opinion on the claim, which will be published in the EFSA Journal. Also negative opinions are published in this journal (Gilsenan, 2011; NDA Panel EFSA, 2011a).

\subsection{Analysis of opinions}

In attempt to understand why most proposed claims on either antioxidants, a type of antioxidants or health effects of antioxidants received negative advices from EFSA, six examples of published negative EFSA opinions and two examples of positive EFSA opinions are analysed. The discussion follows the criteria used by EFSA (Table 2).

\subsubsection{Criterion I - food defined and characterised}

The first criterion for EFSA to assess a health claim is the characterisation of the food or functional ingredient. Examples of proposed health claims not approved by EFSA due to insufficient characterisation are: honey being an antioxidant and polyphenols from processed fruits, vegetables and juices having antioxidant properties. Subsequently, two positive advices on copper and olive oil polyphenols are discussed.

4.3.1.1. Negative opinions. The proposed claim on honey relates to several beneficial properties for honey as a food product, e.g. protecting from oxidative damage and defence against pathogens (NDA Panel EFSA, 2011e). The definition of honey in five proposed claims is described in the Honey regulations 2003 which takes the definition of the Codex Alimentarius in 1981 into account, defining honey as 'the natural' sweet substance produced by bees from the nectar of plants or from secretions of living parts of plants or excretions of plant-sucking insects on the living parts of plants, which the bees collect, transform by combining with specific substances of their own, deposit, dehydrate, store and leave in honeycombs to 'ripen and mature' (Codex Alimentarius Commission (CAC), 2001). However, honey can differ in composition (e.g. in sugar and moisture content) and in botanical sources, with varieties due to the nectar source and the geographical location. Therefore EFSA felt not able to characterise the specific honey for which 
the claim is made, and the opinion on this claim was negative (NDA Panel EFSA, 2011e).

A second claim declares polyphenols from processed fruits, vegetables and juices have antioxidant properties (NDA Panel EFSA, 2011f). The term polyphenols, used for this claim and five other proposed claims, describes a large group of secondary plant metabolites including different substances as flavonoids and phenolic acids, all differing in biological activity. The conditions of use of polyphenols are varying widely in the proposed claims and are based either on the non-specific method of spectrophotometric measurement of total polyphenols, or on the use of antioxidant capacity assays. The spectrophotometric measurement measures the reducing capacity of compounds, leading to an overestimation of the actual polyphenol content due to the measurement of other reducing compounds next to the polyphenols. Antioxidant capacity assays as ORAC (oxygen radical absorbance capacity) are also nonspecific for polyphenol activity on oxidation and measure only activity in vitro. The ingredient was therefore not considered to be sufficiently characterised, and the opinion on this claim was negative (NDA Panel EFSA, 2011f).

4.3.1.2. Positive opinions. One of the proposed claims on copper is 'the protection of body tissues and cells from oxidative damage; antioxidant activity' (NDA Panel EFSA, 2009a). The functional ingredient, copper, is seen as a well-recognised nutrient which is measurable in foods by established methods. As it occurs naturally in foods and is authorised to be added to foods, EFSA considers the ingredient to be sufficiently characterised (NDA Panel EFSA, 2009a).

The second example is the claim on olive oil polyphenols. Olive oil polyphenols are claimed to have several beneficial health effects due to their antioxidant properties. The dossier firstly describes the characterisation of olive oil polyphenols. Although polyphenols are a wide group of secondary plant metabolites with variable biological activity, the major polyphenols in olive oil as hydroxytyrosol and its derivatives are measurable in foods by established methods, and according to EFSA the functional ingredient is thereby characterised (NDA Panel EFSA, 2011d).

4.3.1.3. Implications. The first criterion used by EFSA in evaluating a proposed claim is the definition and characterisation of the food or functional ingredient. The analysis of the opinions described above show that it is important to not only display an explicit characterisation of the food or food ingredient including the active substances of the food, it is also relevant that established methodologies are described which enable measurement of these substances in the food or functional ingredients. The composition of honey is considered to be too variable to characterise its active substances and the measurement methods for polyphenols from processed fruits, vegetables and juices are not considered to be valid methods. Olive oil polyphenols are positively assessed in this regard due to the measurability of hydroxytyrosol and its

Table 3

Assessment criteria scientific opinions and their implications for health claims

$$
\text { Criteria }
$$

I The food or functional ingredient is defined and characterised

II The claimed effect is defined The claimed effect is a beneficial physiological effect

III A cause and effect relationship is established between the consumption of the food or functional ingredient and the claimed effect derivatives (e.g. oleuropein, tyrosol) as the active components in the oil (NDA Panel EFSA, 2009a).

These implications, summarised in Table 3 , raise the issue whether a food or functional ingredient can be properly characterised by only measuring one or a limited number of active components, as is currently requested by EFSA. Food does not constitute of only one active component, alike drugs, and therefore this reductionist approach used in nutrition science (the focus of research on the activity of single active components on single effects) is questionable (Jacobs and Steffen, 2003; Jacobs and Tapsell, 2007). To assess the full effect of nutrition on health, not only the individual constituents should be researched, also the diet itself with its additional components and different interactions might play a role in health (Hoffmann, 2003; Schneider and Hoffmann, 2011).

Next to characterising foods or functional ingredients by only single active components, the focus in nutrition science on a single effect is also debatable. The health effect of food is suggested to be the result of multifactorial physiological effects (Weseler and Bast, 2012). Endpoints capturing these pleiotropic effects of nutrients are needed in nutritional research (Heaney, 2008; Van Ommen and Stierum, 2002). Therefore, although EFSA accurately declines several claims lacking clear characterisation of the active substance, the current approach of EFSA requesting scientific substantiation on single components and single effects is problematic, since the multitude of components and effects might elicit different health effects then shown through testing single components and single effects.

\subsubsection{Criterion II - claimed effect defined and beneficial}

The second criterion checked by EFSA, after appropriate characterisation of the food or functional ingredient, is the definition of the claimed effect and if this claimed effect can be regarded as a beneficial effect on human health. Antioxidant property and the effect of antioxidants on ageing is an example of an insufficiently defined claimed effect. The proposed claim of glutathione being an antioxidant is an example of such an unclear beneficial effect on human health. This is followed by the analysis of the two positive opinions on copper and olive oil polyphenols. Subsequently, the implications raised in the opinions are discussed.

4.3.2.1. Negative opinions. The first claim, that antioxidants included in the diet may help to protect the skin from the effects of ageing is assessed together with 14 other proposed claims on protection of cells from premature ageing (NDA Panel EFSA, 2010b). The scientific studies supporting the claims however lack definitions on different characteristics as 'premature (skin) ageing', 'healthy ageing', 'oxidation-induced ageing', 'ageing process' or 'cellular ageing'. This led EFSA to consider these claims to be too general and non-specific and gave a negative advice (NDA Panel EFSA, 2010b).

The second example involves a claim describing glutathione as antioxidant, contributing to the antioxidant defence system and

Implications

Explicit characterisation of food/functional ingredient with active substances

Relevant, established measures for these substances in the food Effect measurable in vivo

Effect connected to a health outcome, without implying treatment

Human trials on claimed effect with specific substance and its specific conditions in vivo

Show evidence for probable mechanism of action

Supportive evidence from reviews, in vitro and animal studies 
the body's immune response (NDA Panel EFSA, 2010c). This claim, along with 25 other claims on antioxidant activity or content and antioxidant properties, was assumed by EFSA to refer to the capacity on scavenging free radicals and/or to their reducing capacity, measured in vitro in model systems. This information was not considered by EFSA to establish a beneficial physiological effect on human health, and the opinion of EFSA on this claim was therefore negative (NDA Panel EFSA, 2010c).

4.3.2.2. Positive opinions. The proposed claimed effects due to the intake of copper is defined as 'the protection of body tissues and cells from oxidative damage; antioxidant activity'. The effects of oxidative stress, damaging molecules as DNA, proteins and lipids if the reactive oxygen species are not counteracted by the antioxidant network, are seen as negative effects and the claim therefore relates to a beneficial physiological effect according to EFSA, and the claim complies with the second criterion set by EFSA (NDA Panel EFSA, 2009a).

The second example of a positive opinion involves the claim on olive oil polyphenols, reducing oxidative stress and having antioxidant activity and antioxidant properties. These proposed health relationships are reviewed in the second criterion. Proposed claims as 'reduces oxidative stress', 'antioxidant properties', 'lipid metabolism', 'antioxidant activity, 'they protect body cells and LDL from oxidative damages', and 'antioxidant properties' are regarded by EFSA to refer to the protection of low-density lipoprotein (LDL) particles from oxidative damage. The effects of oxidative damage, the damage to molecules as DNA, lipids and proteins when reactive oxygen species are not counteracted by the antioxidant network, are seen as harmful to the body. EFSA considers the protection of these biomolecules from oxidative damage to be of possible physiological benefit (NDA Panel EFSA, 2011d).

4.3.2.3. Implications. The second criterion, defining the claimed effect and evaluating if the effect can be considered beneficial to human health, entails that proposed claims are not accepted when they are vague or too general and not explicitly measurable in vivo. The first negative opinion on antioxidants regarded the claims to be too general and too vague. The opinion on glutathione considered the proposed effect, i.e. radical scavenging, not to be beneficial for health. If the effect is connected to health without being a direct treatment for disease, the effect is regarded as a beneficial physiological effect (Table 3). EFSA therefore favours effects not directly aiming at treatment or preventing a disease, but rather focuses on effects improving health of the consumer, as described in the NHCR (European Parliament and the Council, 2006). Thus single health effects seem easy to claim, as shown by research on the use of plant sterols and plant stanols. The slight reduction of only one risk factor of coronary heart diseases, LDL cholesterol, is accepted as marker for the reducing the risk of coronary heart diseases (NDA Panel EFSA, 2012a). However, new insights challenge the use of solitary biomarkers (Ledford, 2013). The question is raised if these secluded effects can always be considered relevant to human health. Research in the field of nutrition suggests that a single clinical biomarker does not reflect health, since these biomarkers imply the use of end-point markers and a link to a disease or condition, which again is not very suitable to measure the subtle effects of nutrition in maintaining health (Elliott et al., 2007; Weseler and Bast, 2012). Novel markers, developed by clustering different small effects, are needed to measure such subtle effects of nutrition on health in a multi-targeted approach (Weseler and Bast, 2012).

Next to this, several studies hold that the concept of human health should be redefined, since the rather static definition of health as the absence of disease, defined by the WHO in 1948, does not seem to be accurate anymore. Today health is considered mainly a dynamic ability to adapt to circumstances, and needs a more individual approach (Huber et al., 2011; Kussmann et al., 2006; van Ommen et al., 2009; Van Ommen and Stierum, 2002; Weseler and Bast, 2012; World Health Organization, 2006). Upon redefining the health concept, more accurate test measures should be developed to measure the effect of nutrition on maintaining health (Elliott et al., 2007).

The perceived relevance of the consumer is an important consideration when looking at the relevance of the claimed effect to human health, as well as a consumers' understanding of such a health claim. In the NHCR the average consumer is considered to be 'reasonably well-informed and reasonably observant and circumspect, taking into account social, cultural and linguistic factors.' (European Parliament and the Council, 2006). However, in literature the perceived relevance of a health claim is described to be stronger if consumers see the relevance of a product to their own health (Dean et al., 2012; Nocella and Kennedy, 2012). Therefore it is important to consider whether the average consumer, as described in the NHCR, can relate a claim to his or her own health and thereby is able to fully understand a health claim (Nocella and Kennedy, 2012). And although in literature the interest of a consumer in nutritional information is shown to be high, understanding of this information and thereby understanding of health claims is hard to test and therefore evidence is rare (Tarabella and Burchi, 2012; van Trijp, 2009). Consequently, relevance and understandability of the claim are important concerns when introducing a new health claim, which was seen to be an important consideration for EFSA as well in rejecting vague and general claims.

\subsubsection{Criterion III - cause and effect relationship established}

The last criterion in the assessment procedure by EFSA involves a check of the scientific studies provided to substantiate the proposed claim. The evidence can be considered not to be sufficient to result in a positive opinion, as was considered to be the case in the claim on lutein protecting from oxidative damage (vide infra). It might also be that the evidence was considered not to substantiate the proposed claim, as in the case of antioxidant action of beta-carotene (vide infra). The two examples of positive opinions, i.e. on copper and olive oil polyphenols, respectively are also discussed.

4.3.3.1. Negative opinions. Lutein was claimed to be a natural antioxidant, and as such to protect the organism from oxidative damage and to act as a natural way to avoid risks caused by oxidation and peroxidation processes (NDA Panel EFSA, 2011c). Lutein is a carotenoid naturally present in foods and measurable by established methods and therefore sufficiently characterised as functional ingredient. The claim of being a 'natural antioxidant' is considered to refer to the protection of oxidative damage caused by free radicals, which was perceived by EFSA to be a beneficial physiologic effect on human health. Three scientific studies were provided to show the cause and effect relationship of lutein and the protection of oxidative damage. According to EFSA, these studies do not analyse the effects of lutein consumption on markers of oxidative damage in humans, and insufficient scientific evidence was available to establish a cause-effect relationship. This led EFSA to issue a negative opinion on the claim (NDA Panel EFSA, 2011c).

The claim on beta-carotene states that its antioxidant action helps to neutralise free radicals and counteracts cellular ageing, and the involvement of beta-carotene in body tissue protection from UV rays damage (NDA Panel EFSA, 2011b). Beta-carotene is sufficiently characterised as a functional ingredient and the ten claims on 'antioxidant activity' and 'protection of DNA', including the one described above, may be considered to be a beneficial physiological effect to human health, implying to protect from oxidative damage caused by free radicals. The substantiation of these 
proposed claims was checked by reviewing the submitted dossier of scientific evidence, including narrative reviews, consensus opinions and human intervention studies. These first documents, narrative reviews and consensus opinions, were not considered to be relevant in substantiating a health claim, because of the lack of original data to evaluate. The other provided studies in the dossier, the human intervention studies, can be divided into two groups. The first group of intervention studies looked at the effects of beta-carotene with other carotenoids or antioxidant vitamins on non-related health outcomes for these claims. Therefore these studies are not used in substantiating the claim. The second group of intervention studies are studies on the effect of beta-carotene on oxidative damage. These studies are not controlled and use markers (as skin erythema as marker of UV-protection and skin malondialdehyde concentrations as a marker of UV-induced photooxidative damage), all regarded as unreliable markers of oxidative damage to DNA and lipids. Due to the lack of scientific evidence on the suggested health claim EFSA issued a negative opinion on this claim (NDA Panel EFSA, 2011b).

4.3.3.2. Positive opinions. The proposed claim on copper, claiming to protect from oxidative damage, is scientifically substantiated by different studies. Several papers describe the role of copper in the human body, being a component of enzymes as cytochrome $c$ oxidase (involved in electron transport in the respiratory chain) and ceruloplasmin (involved in iron transport in plasma), cofactors and proteins in the body and thereby having mostly a catalytic role. Many copper metalloenzymes are described to act as oxidases, to reduce molecular oxygen. An example of such an enzyme is the superoxide dismutase (SOD) enzyme. This enzyme in the cytosol of human cells defends against oxidative damage from superoxide radicals. The activity of SOD is, next to other factors, related to copper intake. Therefore a cause and effect relationship was established according to EFSA, and the claim was assessed positively (NDA Panel EFSA, 2009a).

To scientifically substantiate the claim of olive oil polyphenols reducing oxidative stress and having antioxidant activity and antioxidant properties, the dossier contains several studies that are not considered to ground the claim. These papers are not seen to be suitable to substantiate the claim, due to testing foods or food ingredients other than olive oil polyphenols and/or study effects different than protection of lipids. Studies that are considered to be relevant to validate the claim are three human intervention studies: (i) a study measuring several significant effects including decreased oxidative damage through plasma-circulating oxidised LDL when consuming higher doses of olive oil polyphenols; (ii) a study showing a significant decrease of concentration of circulating markers of LDL particles with higher phenolic content of the olive oil; and (iii) a double-blind randomised intervention showing both a significant decrease in in vivo plasma-circulating oxidised LDL and a significant increase in ex vivo resistance of LDL to oxidation with a higher phenolic content of the olive oil. Other studies address the bioavailability of the compounds and the possible mechanism of action of olive oil polyphenols on protecting the LDL particles from oxidation, which is thought to be caused by the incorporation of the phenolic compounds in the LDL particles. These studies, along with a short term study and an acute study on the effect of olive oil polyphenols on markers of LDL oxidation, were considered by EFSA to support the claim. Because of the use of appropriate markers of LDL peroxidation and of supportive markers pointing in the same direction, along with evidence for the possible mechanism of action, the claim was assessed positively (NDA Panel EFSA, 2011d).

4.3.3.3. Implications. The third and last criterion in the assessment procedure of a proposed claim used by EFSA is the check on scien- tific substantiation of the claim. Within this criterion, one very clear condition is shown: the claimed effect has to be tested in vivo in the proposed human target group. This claimed effect has to be caused by the food or functional ingredient. To establish this relationship, a human intervention study is regarded as the most convincing proof in the analysed opinions. Evidence on the probable mechanism of action of the food or functional ingredient has to be in the submitted dossier to EFSA, explaining the claimed effect. Supportive evidence can come from reviews, in vitro studies and animal studies, but these studies are never solely used to evoke a positive opinion on a claim. Apparently from the provided examples, not all human intervention trials are accepted as evidence. Not only testing in the proposed target group is important with the appropriate conditions of use, the trials must also have high methodological and statistical quality by e.g. addressing confounding factors, making use of valid biomarkers and having sufficient statistical power (Gilsenan, 2011; NDA Panel EFSA, 2011a). After analysing the described opinions on scientific substantiation of health claims, it is clear that solely the consumption of the specific food or functional ingredient has to be tested on the claimed effect. A significant beneficial effect shown in different intervention trials performed by independent institutions increases the chance of receiving a positive advice of EFSA (NDA Panel EFSA, 2011d).

The implications extracted by analysing the opinions, described in Table 3, raise the question whether the physiological effect of the ingredient is the same when it is consumed under experimental conditions or as part of the total diet. Different interventions can have participants consuming different diets, which may influence the observed effects. Also the bioavailability and bioaccessibility are influenced by the composition of the food and the diet possibly leading to different effects with consumption of the food under regular circumstances (Turgeon and Rioux, 2011; Weseler and Bast, 2012). However, since studies for the substantiation of a claim have to use the specific food carrying the proposed claim and mostly attempts are made to control other dietary factors, there currently is no other way to test the effectiveness of the food.

The second issue raised by these implications is the importance of human intervention trials in nutritional research. This study design is currently the only design deemed appropriate to show a strong causal relationship and its suitability to test effects of drugs (evidence-based medicine) has led to the implementation of the design in nutrition research (evidence-based nutrition) (Blumberg et al., 2010; Heaney, 2008). However, for the evaluation of nutrient effects the design is considered to be less appropriate, due to several issues following from the fact that nutrition will not give rise to similar effects as drugs (Heaney, 2008). As described in the second characteristic, nutrients have pleiotropic effects on health versus one or few outcome measures with drugs, and the relative small effects over long periods of time expected with the intake of specific nutrients (Blumberg et al., 2010; Van Ommen and Stierum, 2002; Weseler and Bast, 2012). Therefore suggestions arise in literature to test nutrition in different experimental set-ups as challenge tests where the robustness of a physiological system is put under pressure and the marker for health is the system's ability to resist or to recover from the impact. These challenge tests are reminiscent of oral glucose tolerance test (OGTT) and the oral lipid tolerance test (OLTT) (Elliott et al., 2007; Pellis et al., 2012; van Ommen et al., 2009; Weseler and Bast, 2012). The use of new study designs to substantiate a health claim might be of more relevance to demonstrate the effects of nutrition in health. Table 3 summarises the findings from the opinions published by EFSA as described above in this section.

Comparing the positively and negatively assessed claims, the evaluation procedure is shown to always follow the same three criteria, as previously described in Table 2 . If the assessment is not 
positive in one of these criteria, the other criteria will not be taken into consideration and a negative assessment on the claim follows. This is generally followed by a negative decision by the EC, rejecting authorisation of the claim.

\section{Conclusion}

The White Paper on Food Safety of 2000, developed after different food scares and crises in the 1990s, advised to take different actions on food matters, with the adoption of the GFL as the foundation of European Food Law. Among the many activities on food, in 2006 the EU adopted legislation to regulate nutrition and health claims on food products. Although EFSA was founded in the GFL to perform independent risk assessment, the agency was requested to review proposed health claims under the NHCR. This paper analysed which criteria EFSA uses to undertake this task, specifically in the assessment of claims on antioxidants. Most claims on antioxidant activity were denied while in the meantime new insights on the mechanisms of action of antioxidants arose. Therefore, reviewing the assessment procedure used by EFSA via claims on antioxidants is very timely.

The criteria-implications as displayed in Table 3 have consequences for research on and development of health claims. Nutrition research and more specifically antioxidant research methodology seems to require a different approach as pointed out in this paper. Our analysis reveals that not only the current view on health should be redefined, it also questions the use of intervention trials as golden standards, and views that the focus on single-targets in nutrition research needs to shift towards a multi-target approach. The ability to adapt as a definition for health entails that health promoting compounds should be investigated under stress conditions. In that regard adequate challenge models are to be developed to review the multi-factorial effects of dietary compounds.

New insights arising from research on the mechanisms of action of antioxidants show the lack of usability of the nutrition and health claim regulation. Next to ROS scavenging, the anti-inflammatory actions of antioxidants and their effects on the endogenous antioxidant synthesis could result in health benefits. However, this complexity of the actions of antioxidants is not recognised by the criteria used to evaluate proposed health claims, nor by the methodologies used to assess the effects of antioxidants. At the start of the assessment procedure under the NHCR, EFSA was only provided with Terms of Reference by the EC to base their assessment criteria on. In case of antioxidants the awareness that these compounds have a broader effect than merely their radical scavenging actions might help to position these compounds more clearly. In that regard the term 'bioactive' compounds has been proposed. The current case study shows the need to develop criteria which are more in line with novel scientific insights into the multitude of effects of nutrition, as exemplified with antioxidants. The apparent mismatch in views on how to assess health promoting effects of dietary compounds should be resolved. Therefore, consultative involvement of stakeholders like industrials, advisors of the regulator, scientists and consumer representatives in this respect is pivotal. Improved embedding of nutritional science in these criteria prevails over stringent regulation.

\section{Conflict of interest}

The authors declare that there are no conflicts of interest.

\section{References}

Aggett, P.J. et al., 2005. PASSCLAIM, process for the assessment of scientific support for claims on foods. Eur. J. Nutr. 44, i1-i2.
Bast, A., Haenen, G.R.M.M., 2013. Ten misconceptions about antioxidants. Trends Pharmacol. Sci. 34, 430-436.

Blumberg, J. et al., 2010. Evidence-based criteria in the nutritional context. Nutr. Rev. 68, 478-484.

Byrne, D., 2002. EFSA: Excellence, integrity and openness. Inaugural Meeting of the Management Board of the European Food Safety Authority Brussels.

Carocho, M., Ferreira, I.C.F.R., 2012. A review on antioxidants, prooxidants and related controversy: natural and synthetic compounds, screening and analysis methodologies and future perspectives. Food Chem. Toxicol.

Codex Alimentarius Commission (CAC), 2001. Revised Codex Standard for Honey. <http://www.codexalimentarius.org/standards/list-of-standards/en/ ? provide=standards\&orderField $=$ fullReference $\&$ sort $=$ asc $\&$ num $1=$ CODEX $>$.

de Vries, H.E. et al., 2008. Nrf2-induced antioxidant protection: a promising target to counteract ROS-mediated damage in neurodegenerative disease? Free Radic. Biol. Med. 45, 1375-1383.

Dean, M. et al., 2012. Perceived relevance and foods with health-related claims. Food Qual. Prefer. 24, 129-135.

Diplock, A.T. et al., 1999. Scientific concepts in functional foods in Europe: consensus document. Br. J. Nutr. 81.

Elliott, R. et al., 2007. Nutrigenomic approaches for benefit-risk analysis of foods and food components: defining markers of health. Br. J. Nutr. 98, 1095-1100.

Ernst, Young, 2012. External Evaluation of EFSA - Final Report. <http:// www.efsa.europa.eu/en/keydocs/docs/efsafinalreport.pdf>.

Europe Press Releases, 2006. Questions and Answers on Health and Nutrition Claims. 200 en. htm?locale $=$ en $>$.

European Commission, 1997. The general principles of food law in the European Union - Commission green paper. COM (1997), 176.

European Commission, 2000. White paper on food safety. COM (1999), 719.

European Commission, 2001. Discussion paper on nutrition claims and functional claims.

European Commission, 2003a. Proposal for a regulation of the European Parliament and of the Council on nutrition and health claims made on foods. <http://eurlex.europa.eu/LexUriServ/LexUriServ.do?uri=COM:2003:0424:FIN:EN:PDF>.

European Commission, 2003b. Proposal for a regulation of the European Parliament and of the Council on nutrition and health claims made on foods. Brussels <http://europa. eu. int/eur-lex/en/com/pdf/2003/com2003_0424en01. pdf>.

European Commission, 2007. Terms of Reference. OJ L. 12.

European Commission, 2008. Commission Regulation (EC) No 353/2008 of 18 April 2008 establishing implementing rules for applications for authorisation of health claims as provided for in Article 15 of Regulation (EC) No 1924/2006 of the European Parliament and of the Council. OJ L. 109.

European Commission, 2010. Commission Regulation (EU) No 365/2010 of 28 April 2010 amending Regulation (EC) No 2073/2005 on microbiological criteria for foodstuffs as regards Enterobacteriaceae in pasteurised milk and other pasteurised liquid dairy products and Listeria monocytogenes in food grade salt. OJ L. 107, 9.

European Commission, 2012a. Commission Regulation (EU) No 432/2012 of 16 May 2012 establishing a list of permitted health claims made on foods, other than those referring to the reduction of disease risk and to children's development and health. OJ L. 55, 1-40.

European Commission, 2012b. EU Register on nutrition and health claims. <http:// ec.europa.eu/nuhclaims/

?event=search\&CFID=335086\&CFTOKEN=bb484f431b227bd1-79366084-B93 6-26BA-

A093EC372F6F1B31\&jsessionid=9312c835f5666f4342c4403366511152f434TR

European Commission, 2013. Commission Regulation (EU) No 536/2013 of 11 June 2013 amending Regulation (EU) No 432/2012 establishing a list of permitted health claims made on foods other than those referring to the reduction of disease risk and to children's development and health. OJ L 160.

European Food Information Council, Functional Foods. <http://www.eufic.org/ article/en/expid/basics-functional-foods/>.

European Food Safety Authority, 2013. About the NDA Panel and the Nutrition Unit. <http://www.efsa.europa.eu/en/nda/aboutnda.htm>.

European Food Safety Authority, 2013 "General function" health claims under Article 13. <http://www.efsa.europa.eu/en/topics/topic/article13.htm>.

European Food Safety Authority, 2013. "New function" health claims under Article 13.5. <http://www.efsa.europa.eu/en/topics/topic/article13-5.htm>.

European Food Safety Authority, 2013. Claims on disease risk reduction and child development or health under Article 14. <http://www.efsa.europa.eu/en/topics/ topic/article14.htm>.

European Food Safety Authority, 2013. EFSA: What we do. <http:// www.efsa.europa.eu/en/aboutefsa/efsawhat.htm>.

European Food Safety Authority, 2013. EFSA: Risk Assessment. <http:// www.efsa.europa.eu/en/efsawhat/riskassessment.htm>.

European Food Safety Authority, 2013. EFSA corporate documents. <http:// www.efsa.europa.eu/en/aboutefsa/keydocs.htm>.

European Food Safety Authority, 2013. EFSA: FAQ on nutrition and health claims. <http://www.efsa.europa.eu/en/faqs/faqnutrition.htm?wtrl=01>.

European Food Safety Authority, 2008. Criteria for the initial screening of Article 13(3) health claims of Regulation (EC) No 1924/2006. <http:// www.efsa.europa.eu/en/ndaclaims13/docs/ndaart13torax01.pdf>.

European Food Safety Authority, 2010. EFSA's Modus operandi for Article 13(3) Health Claims of Regulation (EC) No 1924/2006. <http://www.efsa.europa.eu/ en/ndaclaims13/docs/art13modusoperandi.pdf>. 
European Food Safety Authority, 2012. Petition Nutrition and Health Claims. <http://ec.europa.eu/food/food/labellingnutrition/claims/docs/ petition_nutrition_health_claims_230712_en.pdf>.

European Parliament and the Council, 2002. Regulation (EC) No 178/2002 of the European Parliament and of the Council of 28 January 2002 laying down the general principles and requirements of food law, establishing the European Food Safety Authority and laying down procedures in matters of food safety. OJ L. 31, 1-24.

European Parliament and the Council, 2006. Regulation (EC) No 1924/2006 of the European Parliament and of the council of 20 December 2006 on nutrition and health claims made on foods. OJ L. 404, 9-25.

European Parliament and the Council, 2008. Regulation (EC) No 1334/2008 of the European Parliament and of the Council of 16 December 2008 on flavourings and certain food ingredients with flavouring properties for use in and on foods and amending Council Regulation (EEC) No 1601/91, Regulations (EC) No 2232 96 and (EC) No 110/2008 and Directive 2000/13/EC. OJ L. 354

European Parliament and the Council, 2011. Regulation (EU) No 1169/2011 of the European Parliament and of the Council of 25 October 2011 on the provision of food information to consumers, amending Regulations (EC) No 1924/2006 and (EC) No 1925/2006 of the European Parliament and of the Council, and repealing Commission Directive 87/250/EEC, Council Directive 90/496/EEC, Commission Directive 1999/10/EC, Directive 2000/13/EC of the European Parliament and of the Council, Commission Directives 2002/67/EC and 2008/ 5/EC and Commission Regulation (EC) No 608/2004 Text with EEA relevance. OJ L. 304 .

Flynn, A., 2012. Symposium 2: nutrition and health claims: help or hindrance Scientific substantiation of health claims in the EU. Proc. Nutr. Soc. 71, 120-126.

Forman, H.J. et al., 2014. How do nutritional antioxidants really work: nucleophilic tone and para-hormesis versus free radical scavenging in vivo. Free Radic. Biol. Med. 66, 24-35.

Geraets, L. et al., 2007. Dietary flavones and flavonoles are inhibitors of poly(ADPribose)polymerase-1 in pulmonary epithelial cells. J. Nutr. 137, 2190-2195.

Gilsenan, M., 2011. Nutrition \& health claims in the European Union: a regulatory overview. Trends Food Sci. Technol. 22, 536-542.

Halliwell, B., 1996. Antioxidants in human health and disease. Annu. Rev. Nutr. 16, $33-50$.

Halliwell, B., 2007. Biochemistry of oxidative stress. Biochem. Soc. Trans. 35, 11471150.

Halliwell, B., 2011. Free radicals and antioxidants - quo vadis? Trends Pharmacol. Sci. 32, 125-130.

Hanekamp, J.C. et al., 2013. Nutrition and health - transforming research traditions. Crit. Rev. Food Sci. Nutr.

Hazewindus, M. et al., 2012. The anti-inflammatory effect of lycopene complements the antioxidant action of ascorbic acid and $\alpha$-tocopherol. Food Chem. 132, 954958.

Health and Consumer Protection Directorate General, 2000. Food law from farm to table - Creating a European Food Authority. <http://ec.europa.eu/dgs/ health_consumer/library/press/press82_en.html>.

Heaney, R.P., 2008. Nutrients, endpoints, and the problem of proof. J. Nutr. 138, 1591-1595.

Heim, K.E. et al., 2002. Flavonoid antioxidants: chemistry, metabolism and structure-activity relationships. J. Nutr. Biochem. 13, 572-584.

Hoad, D., 2011. Scientific method and the regulation of health and nutritional claims by the European Food Safety Authority. Bull Sci. Technol. Soc. 31, 123133.

Hoffmann, I., 2003. Transcending reductionism in nutrition research. Am. J. Clin. Nutr. 78, 514S-516S.

Huber, M. et al., 2011. How should we define health? BMJ 343.

Jacobs, D.R., Steffen, L.M., 2003. Nutrients, foods, and dietary patterns as exposures in research: a framework for food synergy. Am. J. Clin. Nutr. 78, 508S-513S.

Jacobs, D.R., Tapsell, L.C., 2007. Food, not nutrients, is the fundamental unit in nutrition. Nutr. Rev. 65, 439-450.

Kussmann, M. et al., 2006. OMICS-driven biomarker discovery in nutrition and health. J. Biotechnol. 124, 758-787.

Langseth, L., 1995. Oxidants, Antioxidants, and Disease Prevention. ILSI Press, Brussels.

Ledford, H., 2013. Cholesterol limits lose their lustre. Revised guidelines for heart health are set to move away from target-based approach. <http:/ www.nature.com/news/cholesterol-limits-lose-their-lustre1.12509?WT.ec_id=NATURE-20130228>.

Levidow, L., Carr, S., 2007. Europeanising advisory expertise: the role of 'independent, objective and transparent' scientific advice in agri-biotech regulation. Environ. Plann. C Gov. Policy 26, 880-895.

Malireddy, S. et al., 2012. Phytochemical antioxidants modulate Mammalian cellular epigenome: implications in health and disease. Antioxid. Redox Signal. 17, 327-339.

Masella, R. et al., 2005. Novel mechanisms of natural antioxidant compounds in biological systems: involvement of glutathione and glutathione-related enzymes. J. Nutr. Biochem. 16, 577-586.

Moors, E.H., 2012. Functional foods: regulation and innovations in the EU. Innovation 25, 424-440.

NDA Panel EFSA, 2009a. Scientific Opinion on the substantiation of health claims related to copper and protection of DNA, proteins and lipids from oxidative damage (ID 263, 1726), function of the immune system (ID 264), maintenance of connective tissues (ID 265, 271, 1722), energy-yielding metabolism (ID 266), function of the nervous system (ID 267), maintenance of skin and hair pigmentation (ID 268, 1724), iron transport (ID 269, 270, 1727), cholesterol metabolism (ID 369), and glucose metabolism (ID 369) pursuant to Article 13(1) of Regulation (EC) No 1924/2006. EFSA J. 7, 1211.

NDA Panel EFSA, 2009b. Scientific Opinion on Water-soluble tomato concentrate (WSTC I and II) and platelet aggregation Scientific substantiation of a health claim related to water-soluble tomato concentrate (WSTC I and II) and platelet aggregation pursuant to Article 13(5) of Regulation (EC) No 1924/2006. EFSA J. 1101.

NDA Panel EFSA, 2010a. Scientific Opinion on the modification of the authorisation of a health claim related to water-soluble tomato concentrate and helps to maintain a healthy blood flow and benefits circulation pursuant to Article 13(5) of Regulation (EC) No 1924/2006 following a request in accordance with Article 19 of the Regulation (EC) No 1924/2006. EFSA J. 8, 1689.

NDA Panel EFSA, 2010b. Scientific Opinion on the substantiation of health claims related to various food(s)/food constituent(s) and protection of cells from premature ageing (ID 1668, 1917, 2515, 2527, 2530, 2575, 2580, 2591, 2620 , $3178,3179,3180,3181,4329,4415)$, antioxidant activity, antioxidant content and antioxidant properties (ID 857, 1306, 2515, 2527, 2530, 2575, 2580, 2591 2629, 2728, 4327, 4365, 4380, 4390, 4394, 4455, 4464, 4507, 4694, 4705), protection of DNA, proteins and lipids from oxidative damage (ID 1196, 1211 $1216,1306,1312,1440,1441,1666,1668,1692,1900,1914,1948,2023,2158$, $2517,2522,2527,2575,2591,2620,2637,2639,2663,2860,3079,3276,3564$ 3818, 4324, 4329, 4351, 4397, 4416, 4424, 4507, 4527, 4528, 4542, 4611, 4629, 4659 ) and bioavailability of anthocyanins in black currants (ID 4220) pursuant to Article 13(1) of Regulation (EC) No 1924/2006. EFSA J. 8, 1752.

NDA Panel EFSA, 2010c. Scientific Opinion on the substantiation of health claims related to various food(s)/food constituent(s) and protection of cells from premature aging, antioxidant activity, antioxidant content and antioxidant properties, and protection of DNA, proteins and lipids from oxidative damage pursuant to Article 13(1) of Regulation (EC) No 1924/2006. EFSA J. 8, 1489.

NDA Panel EFSA, 2011a. General guidance for stakeholders on the evaluation of Article 13.1, 13.5 and 14 health claims. EFSA J. 9, 2135.

NDA Panel EFSA, 2011b. Scientific Opinion on the substantiation of health claims related to beta-carotene and protection of DNA, proteins and lipids from oxidative damage (ID 19,197, 1262, 1460), protection of the skin from UVinduced (including photo-oxidative) damage (ID 178, 197, 1263, 1461, 1968, 2320) and maintenance of the normal function of the immune system (ID 200, 1462) pursuant to Article 13(1) of Regulation (EC) No 1924/2006. EFSA J. 9, 2021.

NDA Panel EFSA, 2011c. Scientific Opinion on the substantiation of health claims related to lutein and protection of DNA, proteins and lipids from oxidative damage (ID 3427), protection of the skin from UV-induced (including photooxidative) damage (ID 1605, 1779) and maintenance of normal vision (ID 1779 2080) pursuant to Article 13(1) of regulation (EC) No 1924/2006. EFSA J. 9, 2030

NDA Panel EFSA, 2011d. Scientific Opinion on the substantiation of health claims related to polyphenols in olive and protection of LDL particles from oxidative damage (ID 1333, 1638, 1639, 1696, 2865), maintenance of normal blood HDLcholesterol concentrations (ID 1639), maintenance of normal blood pressure (ID 3781), "anti-inflammatory properties" (ID 1882), "contributes to the upper respiratory tract health" (ID 3468), "can help to maintain a normal function of gastrointestinal tract" (3779), and "contributes to body defences against external agents" (ID 3467) pursuant to Article 13(1) of Regulation (EC) No 1924/2006. EFSA J. 9, 2033.

NDA Panel EFSA, 2011e. Scientific Opinion on the substantiation of health claims related to: dairy products (ID 1140,1141, 1191), raw or processed food products of animal origin, plus bread and panification products (ID 1193,1194), herbal yeast plasmolysate (ID 1815, 1816), apple polyphenols (ID 2713), rye flour (ID 1266), tomato juice (ID 1202), whey protein and alphalactalbumin (ID $424,430,432,725,1433$ ), "brocco shoots", "broccoli sprout powder" and "Brassica oleracea var. italica (broccoli)" (ID 1362, 1481, 2844, 2845), honey (ID 1159, 1160, 1318, 4678, 4679), and Cucurbita pepo L. (pumpkin) seeds and seed extracts (ID 2029, 2365) pursuant to Article 13(1) of Regulation (EC) No 1924| 2006. EFSA J. 9, 2243.

NDA Panel EFSA, 2011f. Scientific Opinion on the substantiation of health claims related to: flavonoids and ascorbic acid in fruit juices, including berry juices (ID 1186); flavonoids from citrus (ID 1471); flavonoids from Citrus paradisi Macfad. (ID 3324, 3325); flavonoids (ID 1470, 1693, 1920); flavonoids in cranberry juice (ID 1804); carotenoids (ID 1496, 1621, 1622, 1796); polyphenols (ID 1636 $1637,1640,1641,1642,1643)$; rye bread (ID 1179); protein hydrolysate (ID 1646); carbohydrates with a low/reduced glycaemic load (ID 476, 477, 478, 479 602 ) and carbohydrates which induce a low/reduced glycaemic response (ID 727, 1122, 1171); alfalfa (ID 1361, 2585, 2722, 2793); caffeinated carbohydratecontaining energy drinks (ID 1272); and soups (ID 1132, 1133) pursuant to Article 13(1) of Regulation (EC) No 1924/2006. EFSA J. 9, 2082.

NDA Panel EFSA, 2012a. Scientific Opinion on the substantiation of a health claim related to $3 \mathrm{~g} /$ day plant sterols/stanols and lowering blood LDL-cholesterol and reduced risk of (coronary) heart disease pursuant to Article 19 of Regulation (EC) No 1924/2006. EFSA J. 10, 2693.

NDA Panel EFSA, 2012b. Scientific Opinion on the substantiation of a health claim related to cocoa flavanols and maintenance of normal endothelium-dependent vasodilation pursuant to Article 13(5) of Regulation (EC) No 1924/2006. EFSA J $10,2809$.

Nguyen, T. et al., 2004. The pathways and molecular mechanisms regulating Nrf2 activation in response to chemical stress. Free Radic. Biol. Med. 37, 433-441.

Nocella, G., Kennedy, O., 2012. Food health claims - What consumers understand. Food Policy 37, 571-580. 
Owuor, E.D., Kong, A.-N.T., 2002. Antioxidants and oxidants regulated signal transduction pathways. Biochem. Pharmacol. 64, 765-770.

Pellis, L. et al., 2012. Plasma metabolomics and proteomics profiling after a postprandial challenge reveal subtle diet effects on human metabolic status. Metabolomics 8, 347-359.

Preiser, J.C., 2012. Oxidative stress. JPEN, J. Parenter. Enteral Nutr. 36, 147-154.

Reuland, D.J. et al., 2013. The role of Nrf2 in the attenuation of cardiovascular disease. Exerc. Sport Sci. Rev.

Schneider, K., Hoffmann, I., 2011. Nutrition ecology - a concept for systemic nutrition research and integrative problem solving. Ecol. Food Nutr. 50, 1-17.

Silano, M., Silano, V., 2008. The fifth anniversary of the European Food Safety Authority (EFSA): Mission, organization, functioning and main results. Fitoterapia 79, 149-160.

Szajkowska, A., 2009. From mutual recognition to mutual scientific opinion? Constitutional framework for risk analysis in EU food safety law. Food Policy 34, 529-538.

Tarabella, A., Burchi, B., 2012. The role of nutrition and health claims in consumers' perception. Creating educational paths to resolve information asymmetries caused by promotion and marketing activities regarding foodstuffs. Procedia Soc. Behav. Sci. 46, 2173-2177.

Turgeon, S.L., Rioux, L.-E., 2011. Food matrix impact on macronutrients nutritional properties. Food Hydrocoll. 25, 1915-1924.

van der Meulen, B., van der Velde, M., 2008a. Food Law: Development, Crisis and Transition. European Food Law Handbook. Wageningen Academic Publishers, Wageningen, pp. 229-252. van der Meulen, B., van der Velde, M., 2008b. Informed choice: presentation of food products. European Food Law Handbook. Wageningen Academic Publishers, Wageningen.

van der Meulen, B., van der Velde, M., 2008c. The Institutions of the European Community. European Food Law Handbook. Wageningen Academic Publishers, Wageningen, pp. 161-216.

van der Meulen, B.M., 2009. System of food law in the European Union. Deakin Law Rev. 14, 305.

van Ommen, B. et al., 2009. Challenging homeostasis to define biomarkers for nutrition related health. Mol. Nutr. Food Res. 53, 795-804.

Van Ommen, B., Stierum, R., 2002. Nutrigenomics: exploiting systems biology in the nutrition and health arena. Curr. Opin. Biotechnol. 13, 517-521.

van Trijp, H.C., 2009. Consumer understanding and nutritional communication: key issues in the context of the new EU legislation. Eur. J. Nutr. 48, 41-48.

Verhagen, H. et al., 2010. Status of nutrition and health claims in Europe. Arch. Biochem. Biophys. 501, 6-15.

Weseler, A.R., Bast, A., 2010. Oxidative stress and vascular function: implications for pharmacologic treatments. Curr. Hypertens. Rep. 12, 154-161.

Weseler, A.R. Bast, A., 2012. Pleiotropic-acting nutrients require integrative investigational approaches: the example of flavonoids. J. Agric. Food Chem. 60, 8941-8946.

World Health Organization, 2006. Constitution of the World Health Organization. <www.who.int/governance/eb/who_constitution_en.pdf>. 